ARTIGO

\title{
A prevenção e a política sobre drogas em escolas públicas do Distrito Federal
}

\author{
The prevention and the policy of drugs in the Federal District public schools \\ Maria Lizabete Pinheiro de SOUZA ${ }^{1}$ \\ Juliana Alves de Araújo BOTTECHIA ${ }^{2}$ \\ José do Nascimento Rêgo MARTINS ${ }^{3}$ \\ Maraisa Bezerra LESSA ${ }^{4}$ \\ Daisy Rotavio Jansen WATANABE ${ }^{5}$
}

\begin{abstract}
Resumo: O artigo visa apresentar o trabalho desenvolvido pelo Programa de Estudos e Atenção às Dependências Químicas da Universidade de Brasília (PRODEQUI/ UnB), no contexto do Curso de Prevenção ao Uso de Drogas para Educadores de Escolas Públicas, no eixo prevenção do Programa "Crack é Possível Vencer!". Focaliza a dimensão política da prevenção do uso de drogas e apresenta a experiência vivenciada no Distrito Federal em parceria com a Secretaria de Estado de Educação. A pesquisa-ação realizada pelo Polo de Pesquisa-DF possibilitou perceber que a cultura do medo, atrelada a uma visão proibicionista do uso de drogas, ainda é muito presente nas escolas. Não obstante, verifica-se um movimento de transição para um modelo sistêmico, no qual novas possibilidades para a discussão sobre o tema são desveladas.

Palavras-chave: Escolas. Política de prevenção. Drogas. Modelos de prevenção.
\end{abstract}

\begin{abstract}
The article presents the work of the Study Programme on Chemical Dependency Care and the University of Brasilia (PRODEQUI / UnB) in the context of Prevention Course to Drug Use Public School Educators, the shaft prevention of the "Crack is possible Winning! ". Focuses on the political dimension of prevention of drug use and presents the experience lived in the Federal District in partnership with the State Department of Education. Action research conducted by the Center of Research-DF enabled realize that the culture of fear, linked to a prohibitionist view of drug use, is still very present in schools. Nevertheless, there is a transitional move to a systemic model, in which new possibilities for discussion on the topic are unveiled.
\end{abstract}

Keywords: Schools. Prevention policy. Drugs. Prevention models.

Submetido em: 11/02/2015. Revisado em: 11/05/2015. Aceito em: 16/06/2015.

\begin{abstract}
1Psicóloga. Mestre em Educação pela Universidade Católica de Brasília (PUC (DF), Brasil) e em Psicologia pela Universidade de Brasília (UnB, Brasil). Apoio Fundo Nacional do Desenvolvimento da Educação (FNDE, Brasil) E-mail: <marializabetedesouza@gmail.com>.

${ }^{2}$ Química.Doutora em Educação pela Universidade da Madeira (Uma, Portugal). Professora de Química na Secretaria de Estado de Educação do Distrito Federal (SEDF, Brasil) e na Universidade Estadual de Goiás, Campus Formosa (UEG, Brasil). E-mail:<juliana.bottechia@yahoo.com.br>.

${ }^{3}$ Oficial Militar. Especialista em Ciência Política, Direito Público. Gerente da Gerência dos Gabinetes de Gestão Integrada. Conselheira titular do Conselho de Políticas sobre drogas do Distrito Federal. E-mail: <jose.martins@ssp.df.gov.br>.

${ }^{4}$ Socióloga. Mestre em Sociologia pela Universidade Estadual Paulista Júlio de Mesquita Filho (UNESP, Brasil). Professora de Sociologia no IFG. E-mail: <maraisa.sedf@gmail.com>.

${ }^{5}$ Economista. Conselheira, vice-presidente e coordenadora da Câmara Técnica de Prevenção do Conselho de Políticas sobre Drogas do Distrito Federal (CONEN (DF), Brasil). Membro do Comitê Distrital de Enfrentamento ao Álcool e Outras Drogas. E-mail:<pshoiti@uol.com.br>.
\end{abstract}

Argumentum, Vitória (ES), v. 7, n.1, p. 126-137, jan./jun. 2015. 


\section{Introdução}

$\mathrm{E}$ m cenário de ampla discussão sobre a regulamentação do uso de drogas no Brasil e no mundo, esse artigo visa contribuir com esse debate trazendo a experiência do Programa de Estudos e Atenção às Dependências Químicas (PRODEQUI) da Universidade de Brasília (UnB), no âmbito do programa federal "Crack é Possível Vencer!", com foco na parceria realizada com a Secretaria de Estado de Educação do Distrito Federal (SEEDF) para a implementação de uma política sobre drogas na rede pública de ensino do Distrito Federal (DF).

O PRODEQUI/UnB é um laboratório do Programa de Pós-Graduação em Psicologia Clínica e Cultura, do Instituto de Psicologia da UnB, que desde 2004 desenvolve atividades integradas de pesquisa, ensino e extensão. A fim de contribuir com as abordagens científicas relacionadas ao envolvimento do ser humano com as drogas embasa suas ações na perspectiva sistêmica e da complexidade, que, de acordo com Sudbrack (2004), prima por considerar a gama de fatores psíquicos, emocionais, sociais, culturais, familiares e jurídicos que interagem de forma dinâmica no interior da pessoa.

A principal ação do PRODEQUI/UnB é o Curso de Prevenção do Uso de Drogas para Educadores de Escolas Públicas, realizado em parceria com o Ministério da Educação e a Secretaria Nacional de Políticas sobre Drogas (SENAD) do Ministério da Justiça. O curso oferecido para professores de todo o Brasil na modalidade de extensão, em 2012, passou a ser a principal ação de formação continuada para os profissionais da educação, no âmbito do eixo prevenção do programa federal "Crack é Possível Vencer!"

No Distrito Federal, especificamente, o curso foi executado em estreita parceria com a SEEDF por meio da Política sobre Drogas da SEEDF, instituída por meio da Portaria 97/2012 como uma das principais ações da Secretaria no âmbito do Comitê Distrital de Enfrentamento ao Crack e outras Drogas. Tal política buscou orientar toda a rede pública de ensino e os profissionais da educação em relação ao papel da escola no enfrentamento ao uso de drogas.

Na contramão das perspectivas repressoras e proibicionistas, pautadas na pedagogia do medo, e em sintonia com a Política Nacional sobre Drogas na qual se baseia o Programa "Crack é Possível Vencer!", o trabalho do PRODEQUI/UnB tem buscado desmitificar preconceitos e conscientizar os profissionais de educação quanto à importância do papel preventivo da escola em relação ao uso de drogas, propondo a realização de projetos pedagógicos e intersetoriais nas quais os alunos e os professores tornam-se os principais protagonistas do processo.

Para acompanhar e monitorar o andamento desses projetos, em 2014 foram criados polos de pesquisa regionais. O Polo DF, especialmente, é composto por equipe multidisciplinar e intersetorial que busca trazer diferentes olhares para a implementação da política sobre drogas na escola. Ao analisar os projetos desenvolvidos nas escolas percebeu-se um movimento de 
transição entre as abordagens tradicionais pautadas na pedagogia do medo, com viés repressivo e proibicionista, para um enfoque sistêmico que, apesar de não aprofundar o debate entre o proibicionismo e antiproibicionismo, entende o uso de drogas como sintoma - e não causa, como o senso comum vem interpretando - de vulnerabilidades pessoal e social existentes, buscando atuar, portanto, no fortalecimento dos fatores de proteção e na redução dos fatores de risco que podem levar ao uso de drogas.

\section{Breve histórico do desenvolvimento da política sobre drogas no Brasil e no DF (2010-2014)}

Em resposta aos problemas relacionados ao uso do crack e outras drogas disseminado na maioria dos centros urbanos do país, o governo federal, em 20 de maio de 2010, criou o Plano Integrado de Enfrentamento ao Crack e outras Drogas e um Comitê Gestor, com vistas ao enfrentamento ao tráfico, à prevenção, ao tratamento e à reinserção social de usuários de crack e outras drogas ilícitas (BRASIL, 2013). A execução do referido plano se daria de forma descentralizada e integrada, por meio da conjugação de esforços entre a União, os Estados, os Municípios e o Distrito Federal, observados os princípios da intersetorialidade, interdisciplinaridade, integralidade, bem como considerando a importância da participação da sociedade civil e o controle social.

\section{O Plano traz as seguintes recomendações:}

I. Estruturar, integrar, articular e ampliar as ações voltadas à prevenção do uso, tratamento e reinserção social de usuários de crack e outras drogas, contemplando a participação dos familiares e a atenção aos públicos vulneráveis, entre outros, crianças, adolescentes e população em situação de rua;

II. Estruturar, ampliar e fortalecer as redes de atenção à saúde e de assistência social para usuários de crack e outras drogas, por meio da articulação das ações do Sistema Único de Saúde (SUS) com as ações do Sistema Único de Assistência Social (SUAS);

III. Capacitar, de forma continuada, os atores governamentais e não governamentais envolvidos nas ações voltadas à prevenção do uso, ao tratamento e à reinserção social de usuários de crack e outras drogas e ao enfrentamento do tráfico de drogas ilícitas;

IV. Promover e ampliar a participação comunitária nas políticas e ações de prevenção do uso, tratamento, reinserção social e ocupacional de usuários de crack e outras drogas e fomentar a multiplicação de boas práticas;

V. Disseminar informações qualificadas relativas ao crack e outras drogas; e

VI. Fortalecer as ações de enfrentamento ao tráfico de crack e outras drogas ilícitas em todo o território nacional, com ênfase nos Municípios de fronteira (BRASIL, 2010, Art. 2º ${ }^{\text {). }}$.

Neste sentido, pretendia-se, em consonância com a Política Nacional sobre Drogas, promover a integração e a articulação permanente entre as políticas e ações de saúde, assistência social, segurança pública, educação, desporto, cultura, direitos humanos, juventude, dentre outras. Foram deliberadas ações imediatas e estruturantes, tais como a ampliação da rede de atenção à saúde e assistência social para tratamento e reinserção social de usuários 
de crack e outras drogas, bem como o fortalecimento das ações de prevenção ao uso de drogas.

Para tanto, foi previsto a criação de cursos de capacitação e formação continuada que atendessem às demandas dos atores envolvidos tanto na prevenção, como no tratamento, reinserção social e enfrentamento ao tráfico de crack e outras drogas. Além disso, foram previstas ações informativas permanentes em veículos de comunicação, inclusive no Portal Brasil, do governo federal.

Em dezembro de 2011, o governo federal lançou o Programa "Crack, é possível vencer!" (BRASIL, 2011), por meio do qual, destinou R\$ 4 bilhões na execução das ações previstas no Plano Integrado de Enfrentamento ao Crack e outras Drogas. O Programa foi estruturado em três eixos - cuidado, autoridade e prevenção - nos quais se inseriram as ações de tratamento, segurança e prevenção ao uso de drogas, respectivamente. Dentro do eixo de prevenção destaca-se o Curso de Prevenção do Uso de Drogas para Educadores de Escolas Públicas, oferecido pelo PRODEQUI/UnB que além da formação continuada dos educadores de escolas públicas, também objetiva contribuir com o fortalecimento das redes de proteção, integrando órgãos e profissionais da saúde, da assistência social, da segurança pública e da justiça, além da comunidade.

Este curso é oferecido à distância para professores de todo o Brasil com carga horária de 180 horas. Vale ressaltar que, embora tenha integrado o Programa “Crack é Possível Vencer!", ele teve início em 2004, sendo anterior ao referido programa, atingindo 195.000 cursistas de todo o Brasil em seis anos de vigência. Conforme demonstra a Tabela 1, houve um crescimento significativo do número de inscritos ao ser integrado ao programa "Crack é Possível Vencer!", em 2006.

\section{TABELA 1: Comparativo entre o número de} inscritos em seis edições do Curso de Prevenção ao Uso de Drogas para Educadores de Escolas Públicas.

\begin{tabular}{|c|c|}
\hline Edição/ Ano & $\begin{array}{c}\text { Número de Educadores } \\
\text { Inscritos }\end{array}$ \\
\hline 1 edição -2004 & 5.000 \\
\hline 2 edição -2006 & 20.000 \\
\hline 3 edição -2009 & 25.000 \\
\hline 4 edição -2011 & 25.000 \\
\hline 5 edição -2012 & 70.000 \\
\hline 6 edição -2014 & 50.000 \\
\hline Total & 195.000 \\
\hline
\end{tabular}

Fonte: SUDBRACK, et al, 2014.

No Distrito Federal, o programa “Crack, é Possível Vencer!" se desdobrou por meio do Decreto no 32.901 de 03 de maio de 2011 (DISTRITO FEDERAL, 2011), na criação do Comitê Distrital de Enfrentamento ao Crack e outras Droga, composto por 15 secretarias de estado e a Companhia de Planejamento do Distrito Federal (CODEPLAN). Em sintonia com a Política Nacional sobre Drogas, as ações propostas pelo Comitê tinham por princípio a humanização da abordagem ao dependente químico e a prevenção do uso de drogas. Os órgãos que compunham o Comitê assumiram responsabilidades em relação à prevenção e ao enfrentamento ao uso de drogas, devendo prestar contas ao governador trimestralmente sobre $\mathrm{o}$ andamento das ações de sua pasta. 
De acordo com representantes desse Comitê, a escola foi considerada por diversos órgãos governamentais como campo fértil para a realização de ações de prevenção, o que, segundo gestores da SEEDF, tornava a maioria das escolas e dos profissionais de educação agentes passivos no enfrentamento ao uso de drogas, dependentes de programas oferecidos por entidades parceiras, como a Secretaria de Justiça, Cidadania e Direitos Humanos do Distrito Federal (SEJUS) com o Programa Viva a Vida sem Drogas e a Polícia Militar do Distrito Federal com o Programa Educacional de Resistência às Drogas e à Violência (PROERD), implementado à época por meio de Termo de Cooperação Técnica entre a SEEDF e a PMDF, assinado em 2008. Vale destacar que do modo como vinham sendo executados nas escolas, os referidos programas não estavam em sintonia com a Política Nacional sobre Drogas, pois se baseavam no paradigma do medo e não da promoção da saúde, preconizada pela Política Nacional.

Com o intuito de mudar esse cenário, a principal ação da SEEDF, no âmbito do Comitê Distrital, foi a elaboração de uma Política sobre Drogas, por meio da Portaria $\mathrm{n}^{-} 97$ de 29 de junho de 2012 que buscava orientar, articular e coordenar os diversos setores e instâncias da Secretaria de Educação na prevenção do uso de drogas. O documento foi realizado com base nas concepções teóricas do curso de prevenção oferecido pelo PRODEQUI/UnB, segundo o qual o uso de drogas, especialmente na adolescência, está associado à construção da identidade e da autoestima, decorrentes de processos de interação que envol- vem as relações familiares, escolares e socioculturais (BRASIL, 2014).

Com esse foco, a SEEDF, por intermédio do trabalho da Coordenação de Educação em Direitos Humanos (COEDH), procurou ir na contramão do imaginário de grande parte da população que associa os usuários de drogas à criminalidade e à delinquência. Nesse sentido, conforme palestras da COEDH à época, o uso de droga deve ser entendido pelos profissionais da rede pública de ensino como um sintoma de vulnerabilidades pessoais e ou sociais, cuja prevenção se daria não pela coerção, mas pela redução dos fatores de riscos e fortalecimento dos fatores de proteção capazes de afastar os estudantes do mundo das drogas, conforme preconizam os estudos do PRODEQUI/UnB.

\section{Bases Teóricas do Curso de Prevenção do Uso de Drogas para Educadores de Esco- las Públicas}

Partindo do entendimento epistemológico de que "prevenir" significa impedir que aconteça (o mal) e "promover" dar o impulso (ao bem), a ideia da prevenção do uso de drogas defendida pelo PRODEQUI/UnB tira a ênfase da droga (mal) para focar na saúde (bem). Nesse sentido, a proposta de prevenção do PRODEQUI/UnB está pautada na promoção da saúde, indicando "[...] estratégias que enfatizam a transformação de condições de vida e de trabalho que confrontam a estrutura subjacente aos problemas de saúde, demandando uma abordagem intersetorial" (BRASIL, 2014, p. 138), que integre os órgãos e profissionais da saúde, da assis- 
tência social, da educação, entre outros que compõe as redes sociais do sujeito.

O conceito de redes sociais é tanto teórico quando sistêmico e encerra a ideia de uma teia relacional entre pessoas e grupos sociais (SLUZKI,1997). A prática das redes sociais consiste em construir estratégias que aproximem as pessoas de determinada comunidade, prevê o reforço dos vínculos afetivos e permite "[...] a circulação das informações necessárias, troca de experiências, aprendizados recíprocos e construção de soluções coletivas" (SUDBRACK, 2014a, p. 174). A rede social permite integrar na prática, elementos econômicos, sociais e culturais operando mudanças no nível macro e microsssocial (SUDBRACK, 1996).

As redes sociais só podem ser desenvolvidas com base na confiança entre os indivíduos. O modelo de intervenção em redes sociais objetiva promover a saúde restabelecendo os vínculos afetivos entre as pessoas e grupos de forma integrada e integradora. Os atores e instâncias escolares são os nós da rede que se oferecem como pontos de entrada para intervenção. $\mathrm{O}$ plano de prevenção da escola extrapola uma a dimensão pessoal constituindo-se numa dimensão coletiva e institucional, a qual deve estar incluída no Projeto Político-Pedagógico (PPP) da escola, norteador das ações escolares que possibilita a construção identitária da escola, das instâncias educacionais (Conselho Escolar, Grêmio, Associação de Pais e Mestres) e dos agentes escolares (diretores, coordenadores, funcionários, professores, alunos, pais entre outros).
As instituições escolares são redes simbólicas, sancionadas pelo imaginário social que articulam o funcional e o imaginário. No nível institucional que considera o contexto sociocultural, o interventor sistêmico deve prioritariamente reconhecer o outro não somente em sua materialidade biológica, mas em suas tradições e na sua própria, única e irrepetível forma de ser e participar (SCHUST et al., 1999). A ética e a estética da comunidade envolvem a capacidade de ouvir o sofrimento do outro e evitar os processos de exclusão (SAWAIA, 1999).

Segundo Sudbrack (2014b), em relação ao usuário de drogas existem duas visões: a tradicional e a sistêmica. Na visão tradicional, ele é visto como delinquente ou doente, infantilizado e submisso ao controle familiar, o que dificulta a relação com a família e a sociedade. Na visão sistêmica, é percebido como sujeito de direitos, agente de mudança, com autonomia para tomar decisões e negociar regras, o que facilita a sua relação com a família e a sociedade, mas ele sempre deve ser acolhido.

De acordo com essa perspectiva, defendida pelo PRODEQUI/UnB, é fundamental compreender o contexto no qual o sujeito se insere, considerando a gama de fatores internos e externos que interatuam na sua formação. Nesse sentido, as relações escolares devem se materializar em fatores de proteção que fortaleçam a autoestima e a imagem que o estudante tem de si propiciando novos prazeres, pautados em um estilo de vida saudável, e contribuindo para a redução dos fatores de risco que reforçam as vulnerabilidades pessoais e sociais, podendo levar ao uso de drogas. 
Essa abordagem traz à tona a necessidade de práticas educativas que rompam com a cultura do medo - que associa a droga ao terror sem diferenciar criticamente os diferentes tipos de uso - para adotar uma visão sistêmica de educação para saúde, focada no fortalecimento do sujeito em busca de autonomia, exercitada no protagonismo social para uma vivência plena de cidadania. Durante a pesquisa realizada pelo Polo DF, foi possível perceber que, de um modo geral, nas escolas ainda é possível encontrar esses dois modelos preventivos abaixo especificados:

TABELA 2: Comparativo entre dois enfoques sobre prevenção do uso de drogas

\begin{tabular}{|l|l|}
\hline Enfoque do medo & Enfoque sistêmico \\
\hline Controle da oferta: & Redução da demanda:
\end{tabular}

Preocupação em contro-Preocupação em reduzir lar a oferta de drogasa procura por drogas, ilícitas, com pretensão de com limites para crianças acabar com as drogas. e jovens no acesso às drogas lícitas e ilícitas.

\section{Controle externo: Autonomia:}

Criminalização do usuá-Conscientização da porio de drogas, com abor-pulação sobre o uso de dagem policial centradadrogas lícitas e ilícitas. nas drogas ilícitas.

Ampliação da violência Ampliação do conhecique gera insegurança emento e competência paralisia: para ação:

Ênfase no medo e nas Ênfase na autoestima e ameaças, promovendona autoconfiança, proimpotência e inércia. movendo iniciativas para soluções criativas.

Abordagem isolada:Abordagem integrada: Problema reduzido àProblema definido a questão do produto, partir do encontro de atribuindo poder à subs-uma pessoa com um tância sem considerar oproduto em um contexto sujeito. sociocultural.

Repressão: $\quad$ Educação:

Prevenção centrada naPrevenção centrada no fuga do problema, usan-conhecimento da realido um discurso estereo-dade, quebrando tabus, tipado e amedrontador, reconhecendo situações impondo posturas e de-de risco, promovendo a cisões autoritárias. opção pela saúde e pela vida.

\section{Questão individual:Questão relacional:}

Envolvimento com dro-Envolvimento com drogas visto como um pro-gas visto como $\mathrm{m}$ problema pessoal, tratadoblema de relações tratacomo um processo psico-do como processo de lógico individual. mudanças no contexto familiar.

Soluções hierarquizadas Soluções participativas e e parciais: contextualizadas:

Isolamento dos usuários Mobilização dos recursos do convívio social, trans-comunitários, construinferindo o problema para do vínculos afetivos, especialistas. redes sociais, integrando os diferentes saberes.

Fonte: SUDBRACK (2014a, p. 172).

A partir dessa perspectiva sistêmica deve se inovar as formas de intervenções pedagógicas, pois o jovem deixa de ser “[...] considerado negativo e destrutivo e passa a ser o protagonista das mudanças necessárias à evolução e à melhora nas relações da família ou dos demais sistemas nos quais interage" (SUDBRACK, 2014, p. 164). Nesse enfoque, a escola é considerada um espaço privilegiado para a prevenção e a construção dos sujeitos. Os educadores são vistos como mediadores do processo de desenvolvimento da personalidade do educando e construção das subjetividades (DUBET; MARTUCCELLI, 1996), inerentes ao processo de aprendizagem.

Torna-se necessário, portanto, desconstruir visões preconceituosas em relação ao uso e ao usuário, redimensionando a relação professor-aluno-comunidade e a prá- 
tica pedagógica na escola que, para além de um trabalho pedagógico contra o uso de drogas, deve-se desenvolver ações contínuas e processuais nas quais o estudante sinta-se pertencente e valorizado nas relações escolares, construindo redes de proteção que reduzam os riscos de envolvimento com os problemas relacionados ao uso de drogas.

\section{O trabalho do Polo de Pesquisa-DF do PRODEQUI/UnB}

Partindo do referencial teórico e metodológico proposta no curso do PRODEQUI/UnB, a Política sobre Drogas da SEEDF buscou orientar os diversos setores e instâncias da rede pública de ensino quanto à importância da escola na prevenção do uso de drogas, fomentando o desenvolvimento de ações e projetos atrelados aos Projetos Políticos Pedagógicos das escolas e a prática pedagógica do professor (a) de forma contínua e processual. O referido documento ainda prevê que:

Os programas, projetos e as ações de prevenção do uso de drogas desenvolvidos nas Unidades Escolares devem utilizar de diferentes formas de intervenção - isoladamente ou concomitantemente - a depender de cada realidade, a saber:

I - conhecimento científico que forneçam informações imparciais, a partir das quais os estudantes possam fazer suas escolhas com autonomia e criticidade;

II - educação afetiva que visa melhorar os fatores psicológicos e de interrelações - autoimagem, autoestima, habilidade em interagir e responder de forma saudável às pressões sociais -, partindo da compreensão de que os indivíduos internamente melhor organi- zados estão menos sujeitos a fazer uso de drogas;

III - oferta de alternativas e oportunidades que propiciem novos desafios, prazeres e realizações sem a necessidade do consumo de drogas;

IV - educação para a saúde focada em hábitos saudáveis e na melhoria da qualidade de vida;

$\mathrm{V}$ - educação que não se limite à prevenção às drogas, mas oportunize a formação integral do ser (DISTRITO FEDERAL, 2012, Art. 7º).

Esta perspectiva procurou rebater as práticas repressivas, atreladas ao modelo do medo, para adotar posturas mais focadas na promoção da saúde integral e no fortalecimento dos fatores de proteção que tendem a afastar os estudantes do mundo das drogas. Com o intuito de capacitar os profissionais da educação para a implementação dessas ações, a SEEDF realizou ampla divulgação do Curso de Prevenção do Uso de Drogas para Educadores de Escolas Públicas ao mesmo tempo em que promoveu - em parceria com o PRODEQUI/UnB - o curso presencial “O lugar da escola na prevenção ao uso de drogas: desafios, possibilidades e metodologias para prevenção pelos educadores" para os coordenadores e gestores das esferas central e intermediária, responsáveis por levar e acompanhar as políticas educacionais para as escolas.

Um dos principais desdobramentos desse curso com coordenadores e gestores, foi o "Projeto de Pesquisa do Polo DF: construindo redes, fortalecendo escolas", que pretendeu mapear e acompanhar os projetos apresentados no âmbito da $5^{a}$ edição do curso; analisar a efetividade da participa- 
ção dos profissionais da educação nessa edição e fomentar a política de prevenção do uso de drogas da SEEDF. Esse projeto de pesquisa, no qual participaram 12 pesquisadores do Polo DF, foi realizado nas seguintes etapas:

a) Análise documental para o mapeamento dos projetos enviados pelos cursistas ao final da $5^{\mathrm{a}}$ edição do curso. Nessa parte do trabalho, foram focalizados alguns pontos como a caracterização da escola, o envolvimento dos participantes, a população atingida, as ações previstas e realizadas.

b) Formulação, aplicação e análise de um questionário aplicado aos cursistas egressos da $5^{\underline{a}}$ edição do curso. O propósito desse questionário foi salientar as seguintes questões basicamente: a satisfação do cursista ao realizar um projeto de prevenção, a mobilização da rede interna e externa da escola, as articulações com as políticas de prevenção e programas educacionais, as conquistas, as dificuldades e as demandas na realização de projeto de prevenção.

c) Pesquisa de campo, ou seja, visita dos pesquisadores, com o apoio dos coordenadores das regionais de ensino, a algumas das escolas do DF que apresentaram projetos, a fim de realizar um trabalho efetivamente em rede. Nesse momento, foi realizada observação participante, por meio de entrevistas com diferentes atores escolares.

Com a referida pesquisa, foi possível perceber que o curso do PRODEQUI/UnB consegue oferecer subsídios teóricos e práticos para o desenvolvimento da política nacional e local sobre drogas, bem como para a maximização de fatores de proteção e a minimização dos fatores de risco no interior da escola. O curso fomenta a articulação da rede interna e externa da escola; o acolhimento do aluno no contexto escolar; o protagonismo de professores e alunos; contribui para a melhoria da autoestima dos alunos, professores e da comunidade escolar, bem como para a construção de novos projetos de vida.

Entretanto, observa-se que apesar dos esforços contínuos para implementação de um novo modelo de prevenção, muitos professores ainda pautam suas ações no paradigma do medo e da repressão, sentindo-se inseguros como protagonistas no desenvolvimento de ações preventivas. A ideia de projetos voltados para a visão sistêmica e da educação para a saúde está presente em muitas escolas, mas, na prática, não é devidamente objetivada, em grande medida, em virtude do medo em lidar com a temática, da falta de condições estruturais e da dificuldade de consolidação de uma equipe de trabalho para apoiar e acompanhar os projetos nas escolas.

Uma das tarefas a serem realizadas é o estabelecimento de ações que ajudem na inovação da prática pedagógica e na construção de redes cooperativas e colaborativas entre os diferentes atores escolares e também intervenções que envolvam os familiares e a comunidade no processo educativo. As ações do Polo de PesquisaDF favoreceram um novo olhar sobre a prática de prevenção do uso de drogas nas escolas visitadas, possibilitando uma maior troca de experiências nas unidades escolares, nas regionais de ensino e nas rodas de saberes em parceria com a Escola 
de Aperfeiçoamento de Profissionais da Educação (EAPE) da SEEDF.

\section{Conclusão}

A proposta do governo federal de implementação do programa "Crack é Possível Vencer!" se desdobrou na criação de comitês de enfrentamento ao crack e outras drogas nos Estados e no Distrito Federal, por meio dos quais diferentes órgãos governamentais assumiram responsabilidades nos campos da segurança, tratamento e prevenção.

No Distrito Federal, as escolas apareceram como importante espaço para o desenvolvimento dessas ações, especialmente as de caráter preventivo. Na prática, materializou-se no espaço escolar o conjunto de disputas políticas e ideológicas acerca dos modelos de prevenção (medo versus sistêmico), tornando a prática pedagógica dos educadores repleta de contradições. Ao tempo em que algumas escolas buscam romper com o modelo vigente por meio de projetos focados no protagonismo do aluno e do professor, ainda se percebe uma pedagogia do medo, que torna os sujeitos escolares reprodutores do velho jargão "diga não às drogas".

A construção de uma política de prevenção do uso de drogas é um processo longo e requer uma mudança cultural. É algo que deve envolver diversos atores escolares e acionar diferentes níveis e instâncias das redes interna e externa da escola. Um dos aspectos mais difíceis na efetivação dos projetos de prevenção é o alinhamento das concepções políticas e ideológicas dos diversos profissionais e instituições envolvidos. A falta de um referencial comum, a dificuldade de um diálogo profícuo e a existência de posições ideológicas arraigadas favorecem a reprodução de práticas pedagógicas ainda baseadas no senso comum, reforçando o medo a repressão e o proibicionismo. Não obstante, vivencia-se um momento de transição apontando para uma visão sistêmica que encerra novas formas de abordar a temática nas escolas.

Agradecimentos: Aos interlocutores da pesquisa e suas respectivas instituições.

\section{Referências}

BRASIL. Casa Civil. Decreto № 7.179, 20 de maio de 2010. Institui o Plano Integrado de Enfrentamento ao Crack e outras Drogas, cria o seu Comitê Gestor, e dá outras providências. Diário Oficial da União, Brasília (DF), 21 maio 2010. Disponível em:

$<$ http://www.planalto.gov.br/ccivil_03/_At o2007-2010/2010/Decreto/D7179.htm>.

Acesso em: 5 jan. 2015.

BRASIL, Ministério da Justiça. Cartilha crack, é possível vencer: enfrentar o crack. Compromisso de todos. Brasília (DF), 2013. Disponível em:

$<$ http://conselheiros6.nute.ufsc.br/wpcontent/uploads/avea/conteudo/cartilha_c rack,_ae_possivel_vencer.pdf $>$. Brasília (DF): Conselho Nacional de Segurança Pública. Acesso em: 5 jan. 2015.

BRASIL. Ministério do Desenvolvimento Social e Combate à Fome. Crack é possível vencer: oficinas de alinhamento conceitual. Texto orientador. Brasília (DF), 2011. 
BRASIL.Ministério da Justiça. Curso de prevenção do uso de drogas para educadores de escolas públicas. 6. ed. Brasília (DF): Secretaria Nacional de Políticas sobre Drogas, 2014.

DISTRITO FEDERAL (Brasília). Secretaria de Estado de Educação do Distrito Federal. Política sobre Drogas da Secretaria de Estado de Educação do Distrito Federal, publicada por meio da Portaria no 97 de 13 de junho de 2012. Diário Oficial do Distrito Federal, n. 127, de 29 de junho de 2012.

DISTRITO FEDERAL (Brasília). Decreto $\mathrm{n}^{\underline{0}}$ 32.901 de 3 de maio de 2011. Dispõe sobre o Comitê de Enfrentamento ao Crack e outras Drogas. Diário Oficial do Distrito Federal, n. 84, p. 11, 4 maio 2011. Disponível em: $<$ http://sintse.tse.jus.br/documentos/2011/ Mai/4/decreto-nb0-32-901-de-03-de-maiode-2011-dispoe>. Acesso em: 5 jan. 2015.

DUBET, F.; MARTUCCELLI, D. A L'école - sociologie de l'expérience scolaire.

Bordeaux: Éditions du Seuil, 1996.

SAWAIA, B (Org.). Artimanhas da exclusão. Petrópolis: Vozes, 1999.

SCHUST, J. P. et al. Redes, vínculos y subjetividad su recomposicion como objetivo terapêutico. Buenos Aires: Lugar Editorial, 1999.

SLUZKI, C. E. A Rede Social na Prática Sistêmica: alternativas terapêuticas. São Paulo: Casa do Psicólogo, 1997.

SUDBRACK, M. F. O. Construindo Redes Sociais: Metodologia de Prevenção à Dro- gradição e à Marginalização de Adolescentes de Famílias de Baixa Renda. In: R. M. Macedo. (Org.). Família e comunidade. São Paulo: Associação Nacional de Pesquisa em Pós-graduação, 1996. p. 84113.

SUDBRACK, M. F. O. Fatores de risco e de proteção associados ao uso de drogas na adolescência. Relatório de consultoria. Rio de Janeiro: MEC/SEED/SALTO, 2004.

SUDBRACK, M. F. O. Drogas e Complexidade: do caos à transformação. p. 162166, In: BRASIL. Secretaria Nacional de Políticas sobre Drogas. Curso de prevenção do uso de drogas para educadores de escolas públicas. 6. ed. Brasília (DF): Ministério da Justiça; 2014.

SUDBRACK, M. F. O. O trabalho comunitário e a construção de redes sociais. p. 171-174. In: BRASIL. Secretaria Nacional de Políticas sobre Drogas. Curso de prevenção ao uso de drogas para educadores de escolas públicas. 6. ed. Brasília (DF): Ministério Justiça, 2014a.

SUDBRACK, M. F. O. Acolhendo adolescentes em situação de risco pelo envolvimento com drogas no contexto de vulnerabilidade social e pobreza. p. 184-186, In: BRASIL. Secretaria Nacional de Políticas sobre Drogas. Curso de prevenção do uso de drogas para educadores de escolas públicas. 6. ed. Brasília (DF): Ministério da Justiça; 2014b.

SUDBRACK, M. F. O.; CONCEIÇÃO, M. I. G.; LEITE, L.; NOGUEIRA, R.; SEIDL, E. M. F.; RÖHE, D.; PÓVOA, M. L. de S.; PRODEQUI. Curso a Distância sobre Pre- 
venção do Uso de Drogas para Educadores de Escolas Públicas. Painel. Seminário "Articulando Ações" COMFOR da Universidade de Brasília. UnB. Instituto de

Psicologia. Departamento de Psicologia

Clínica. Brasília: 26 de novembro de 2014. 